\title{
Microbial diversity associated to the intestinal tract of soil invertebrates
}

\author{
Dayana da Silva Correia ${ }^{\mathrm{a}, *}$, Samuel Ribeiro Passos ${ }^{\mathrm{b}}$, Diogo Neves Proença ${ }^{\mathrm{c}}$, \\ Paula Vasconcelos Morais ${ }^{\mathrm{c}}$, Gustavo Ribeiro Xavier ${ }^{\mathrm{d}}$, Maria Elizabeth Fernandes Correia ${ }^{\mathrm{d}}$ \\ a Universidade Federal Rural do Rio de Janeiro, Programa de Pós Graduação em Ciência Tecnologia e Inovação em Agropecuária - Binacional, Seropédica, Rio de Janeiro, \\ Brazil \\ ${ }^{\mathrm{b}}$ Universidade Federal Rural do Rio de Janeiro, Departamento de Ciência do Solo, Seropédica, Rio de Janeiro, Brazil \\ ${ }^{\mathrm{c}}$ Department of Life Sciences and CEMMPRE, FCTUC, University of Coimbra, 3000-456 Coimbra, Portugal \\ d Empresa Brasileira de Pesquisa Agropecuária, Seropédica, Rio de Janeiro, Brazil
}

\section{A R T I C L E I N F O}

\section{Keywords:}

Saprophagous invertebrates

Microbial diversity

DGGE analysis

\begin{abstract}
A B S T R A C T
Interactions between saprophagous invertebrates and microbes are essential for the maintenance and functioning of soil ecosystems, as they directly affect the degradation of organic matter and the nutrient cycle. The intestinal tract of invertebrates is inhabited by a diversity of microbes, and it is closely associated with the food ingested. The aim of this work was to evaluate the profile of prokaryotes associated with the intestinal tract of three invertebrate species. The species of invertebrates Trigoniulus corallinus was collected and incubated in the experiment, after 5 days of incubation we observed the uninduced colonization of two invertebrate species Cubaris murina and Pycnoscelus surinamensis. Therefore, the three species were evaluated in the same way, after 60 days of incubation. The diet supplied comprised different vegetal residues, with distinct carbon/nitrogen compositions. Six treatments were evaluated. After 60 days, five individuals of each species were randomly selected, by removing the posterior third of the intestinal tract. These specimens were next subjected to DNA extraction. The PCR/DGGE analysis was carried out using the 16S rDNA, for the domain Bacteria and the phylum Actinobacteria. DGGE bands were cloned and sequenced using the Bacterial domain. In multivariate analyzes, individuals of the same species after 60 days of incubation, were strongly grouped. These results may be in accordance with the environmental criteria of the host itself, stage of development, phylogeny and diet. Thus, the investigation of the intestinal microbiota, provides relationships between invertebrates and their intestinal bacterial communities. In view of this information, we used the technique of sequencing cloned DGGE bands to quantify the diversity of microorganisms present in the intestinal tract of the studied invertebrates. The phylum Firmicutes, Bacteroidetes, and Proteobacteria were identified by sequencing the cloned bands; Proteobacteria presented the highest number of genera, comprising Enterobacter, Buttiauxella, Serratia, Kluyvera, and Pantoea.
\end{abstract}

\section{Introduction}

Soil microbial communities differ significantly (Robe et al., 2003), and present the highest levels of prokaryotic diversity among known habitats (Roesch et al., 2007). Thus, it is important to study ecological aspects in order to investigate the associations of microbes and invertebrates inhabiting the soil.

In general, diversity and evolutionary success of the invertebrates partially relies on innumerable associations with beneficial microbes that are known to optimize nutrient-poor diets, to assist in digesting recalcitrant food components, protect against predators, parasites and pathogens, and contribute to inter- and intraspecific communication
(Engel and Moran, 2013). Processes shaping this association are central questions in research, although still poorly understood. The microbiota might co-evolve with its hosts and establish a close relationship (Koch et al., 2013). In these associations, the host immune system can actively shape the microbiota, while microbiota components might adapt, in turn, to different hosts and environments, and provide potentially important functions to the host itself (Ochman et al., 2010; Bevins and Salzman, 2011; Frese et al., 2011; Brucker and Bordenstein, 2011).

Investigating symbiotic relationships between microbes and invertebrates is one of the main fields of soil microbial ecology. Symbiosis involves the coexistence of two or more species, with the highest degree of association, both outside and inside tissues and organs (Byzov et al.,

\footnotetext{
* Corresponding author.

E-mail addresses: dayanabio83@gmail.com (D. da Silva Correia), pvmorais@ci.uc.pt (P.V. Morais), gustavo.xavier@embrapa.br (G.R. Xavier), elizabeth.correia@embrapa.br (M.E.F. Correia).
} 
2009).

The digestive system of soil invertebrates contains evolutionarily diverse microbes. This implies the occurrence of several associations, one of which is responsible for the maintenance of the soil ecosystem, with processes of organic matter decomposition and nutrients cycle. A well-known example is the symbiosis of the digestive tract of termites and their function ( $\mathrm{Li}$ et al., 2006). Besides termites, studies of symbiosis of other species of invertebrates with microbes have also been carried out in oligochaetes, diplopods, isopods, and others (König and Varma, 2006).

Microbial colonization acts as an indicator of high-quality food, thereby stimulating consumption (Zimmer et al., 2003). This may be due to microbial activity enhancing palatability and nutritive quality of the leaf litter (e.g.,by decreasing the C:N ratio and the content of phenolic compounds) prior to ingestion by isopods (Bouchon et al.,2016).

Changes in the use of the land and vegetable waste supply alter invertebrates' diet, which will consequently change the population of microbes that can be found in the intestinal tract as well as the rates of decomposition process. However, the nutritional interactions of the intestinal microbiota can increase invertebrates' survival, against optimal diets. This improves digestive efficiency, and provides digestive enzymes and vitamins (Dillon and Dillon, 2004).

The plant tissues present in their composition cellulose representing more than $50 \%$ of the foliage and $>90 \%$ of the woody tissues. The physical disruption of plant material by chewing insects increases the availability of cellulose to enzymes (Douglas, 2009). Distribution of cellulase genes among insects has yet to be explored in detail either from a phylogenetic perspective or in relation to insect feeding habits (Douglas, 2009). Plant-parasitic nematodes, cockroaches and termites were among the first to be proven to carry cellulase genes, recently these genes have also been unambiguously demonstrated in other taxa, such as other insects, Gastropoda, Crustacea and Annelida (Cragg et al., 2015).

Given that the diet is considered one of the main factors determining the populations of gut microbes in invertebrates (Ley et al., 2008; Staubach et al., 2013), the aim of this study was to investigate the structure of bacterial community in three species of saprophagous invertebrates, important in the fragmentation of plant residues and decomposition of organic matter. These are: the millipede Trigoniulus corallinus, the terrestrial isopod Cubaris murina (Brandt, 1833), and the cockroach Pycnoscelus surinamensis (Linnaeus, 1758). It is important to report that the initial goal of this work was to investigate only the structure of the bacterial community in one invertebrate species, the millipede T. corallinus, which was collected in compost piles, incubated, and fed with legumes, grasses, and recalcitrant materials. However, two weeks after the start of the experiment, the spontaneous colonization of C. murina (Brandt, 1833) and the cockroach P. surinamensis was observed (Linnaeus, 1758).

In order to relate the bacterial structure to the diets provided, a multivariate analysis was performed using the main components (PCA), while cloning analysis was subsequently carried out on bands extracted from the DGGE gel.

\section{Materials and methods}

\subsection{Invertebrate collection and intestinal tract extraction}

Invertebrates were obtained from an Embrapa Agrobiology field experiment at the Integrated Agroecological Production System (IAPS), located in the municipality of Seropédica, RJ, located between the parallels $22^{\circ} 49^{\prime}$ and $22^{\circ} 45^{\prime} \mathrm{S}$ and the meridians $43^{\circ} 23^{\prime}$ and $43^{\circ} 42^{\prime} \mathrm{W}$, in average altitude of $33 \mathrm{~m}$, in the Baixada Fluminense. The climate of the region, according to the classification of Köopen, is of type Aw (Tropical Climate with dry season). The soil of the experimental area was classified as Red-Yellow Argissolo (EMBRAPA, 2006).

These experiments were repeated twice, with the aim to compare
Table 1

Treatments of vegetable residues supplied to the diplopod of the species Trigoniulus corallinus (Gervais, 1847).

\begin{tabular}{lllll} 
Treatments & Legumes & Grass & $\begin{array}{l}\text { Recalcitrant } \\
\text { materials }\end{array}$ & "C/N ratios \\
\hline T1 & Flemingia 30\% & Paspalum 40\% & cardboard 30\% & 134,85 \\
T2 & Flemingia 30\% & Paspalum 40\% & corncob 30\% & 46,53 \\
T3 & Flemingia 30\% & Paspalum 40\% & coconut fiber 30\% & 47,63 \\
T4 & Gliricidia 30\% & Paspalum 40\% & cardboard 30\% & 127,67 \\
T5 & Gliricidia 30\% & Paspalum 40\% & corncob 30\% & 39,36 \\
T6 & Gliricidia 30\% & Paspalum 40\% & coconut fiber 30\% & 40,45 \\
\hline
\end{tabular}

* C/N: Carbon/Nitrogen.

the data. Both experiments were used, with different organic residues, lignocellulosic compositions, and distinct carbon/ nitrogen $(\mathrm{C} / \mathrm{N})$ ratios. The residues that were added were based on legumes: Flemingia (Flemingia macrophylla) (Willd.), Gliricidia (Gliricidia sepium) (Jacq), bahiagrass (Paspalum notatum) (Flügge), and recalcitrant materials such as cardboard, corncob, and coconut fiber. The latter were subsequently supplied to and consumed by diplopods of the species Trigoniulus corallinus (Gervais, 1847; Diplopod: Spirobolida). In this experiment, $500 \mathrm{~mL}$ of $T$. corallines, which account for approximately 900 individuals, were intentionally added as composting agents of these residues, for a period of 60 days, under controlled humidity and ambient temperature conditions. The other two species of invertebrates that were investigated in this study, Pycnoscelus surinamensis (Linnaeus, 1758) (Blattodea: Blaberidae) and Cubaris murina (Brandt, 1833) (Crustacea: Isopoda), spontaneously colonized the experiment. As shown in Table 1, the experiment consisted of six treatments with four repetitions, carried out in blocks and randomly distributed.

Five individuals of each species were randomly selected per treatment, according to the methodology of Tokuda and Watanabe (2007). These were anesthetized in ether for $10 \mathrm{~min}$, disinfested superficially with $70 \%$ alcohol, and dissected with the aid of a magnifying glass. The entire digestive system was harvested; the hindgut was sectioned, and immersed in $1.0 \mathrm{~mL}$ of Ringer's solution: $47 \mathrm{mM} \mathrm{NaCl}, 183 \mathrm{mM} \mathrm{KCl}$, and 10 mM Tris-HCl, at pH 6.8 (Cazemier et al., 1997).

\subsection{Extraction of DNA from the bacterial community associated with the intestinal tract of saprophagous invertebrates}

After harvesting the hindgut, a sample of about $1 \mathrm{~g}$ was removed to extract DNA from adhered microbes, and placed in $1 \mathrm{~mL}$ of Ringer's solution. The samples were vortexed for $30 \mathrm{~s}$ at full speed, left for $15 \mathrm{~min}$ in a refrigerator, and sonicated for $45 \mathrm{~s}$. The microtubes were centrifuged for $15 \mathrm{~min}$ at $9300 \mathrm{~g}$. The supernatant was discarded, and the pellet was subjected to DNA extraction, performed using the commercial kit "Ultra Clean Soil DNA Isolation Kit" (MOBIO), according to the manufacturer's instructions. The extraction efficiency of purified genomic DNA was confirmed by electrophoresis, running the samples in a $1 \%$ agarose gel.

\subsection{PCR amplification}

The analyses of the structures of the bacterial community found in the intestinal tract of the studied saprophagous organisms were carried out by PCR-DGGE. For the domain Bacteria, total DNA template was used to amplify the 16S rDNA variable region V6 - V8 using 968GC and 1401R primers (Heuer et al., 1997) (Table 2). The PCR reaction was performed in a final volume of $30 \mu \mathrm{L}$, which contained $3 \mu \mathrm{L}$ of DNA template, $1.25 \mu \mathrm{M}$ of $\mathrm{MgCl}_{2}, 0.25 \mu \mathrm{M}$ of dNTP, $2.5 \mathrm{U}$ of Taq DNA polymerase enzyme, Kit PCR - Master Mix 2X (Promega), and $0.2 \mu \mathrm{M}$ of each primer. The reaction was conducted in a thermocycler under the following conditions: initial denaturation at $93^{\circ} \mathrm{C}$ for $5 \mathrm{~min}, 35$ cycles of denaturation at $93^{\circ} \mathrm{C}$ for $1 \mathrm{~min}$, annealing at $62^{\circ} \mathrm{C}$ for $1 \mathrm{~min}$, extension 
Table 2

Nucleotide sequences and target groups of primers used to amplify the fragment of the 16S rDNA gene by PCR/DGGE.

\begin{tabular}{|c|c|c|c|}
\hline 16S rRNA Primers & Sequences $\left(5^{\prime}-3^{\prime}\right)$ & Target Group & References \\
\hline $27 \mathrm{~F}$ & AGA GTT TGA TCC TGG CTC AG & Bacteria & Lane (1991) \\
\hline 1492R & ACG GCT ACC TTG TTA CGA CTT & Universal & Lane (1991) \\
\hline $968 F^{*} \mathrm{GC}$ & AAC GCG AAG AAC CTT AC & Universal & Heuer et al. (1997) \\
\hline $1401 \mathrm{R}$ & CGG TGT GTA CAA GGC CCG GGA ACG & Bacteria & Heuer et al. (1997) \\
\hline $243 \mathrm{~F}$ & GGA TGA GCC CGC GGC CTA & Actinomycetales & Heuer et al. (1997) \\
\hline $341 F^{*} \mathrm{GC}$ & CCT ACG GGA GGC AGC AG & Bacteria & Muyzer et al.(1993) \\
\hline $907 \mathrm{R}$ & CCG TCA ATT CCT TTG AGT TT & Universal & Lane (1991) \\
\hline
\end{tabular}

* To stabilize bands migration during DGGE, a GC rich sequence was attached to the 5' end of the primer: 5' CGCCCGCCGCGCGCGGCGGGCGGGGCGGGGGCA CGGGGGG-3'. (Muyzer et al., 1993).

at $72{ }^{\circ} \mathrm{C}$ for $2 \mathrm{~min}$, followed by a final extension at $72{ }^{\circ} \mathrm{C}$ for $10 \mathrm{~min}$.

For the amplification of the phylum Actinobacteria, we used a DNA template, and the $243 \mathrm{~F}$ and $1401 \mathrm{R}$ primers (Heuer et al., 1997) (Table 2). The PCR reaction was carried out in a final volume of $30 \mu \mathrm{L}$; the reaction mixture contained: $3 \mu \mathrm{L}$ of DNA template, $1.25 \mu \mathrm{M}$ of $\mathrm{MgCl}_{2}, 0.25 \mu \mathrm{M}$ of dNTP, $2.5 \mathrm{U}$ of Taq DNA polymerase enzyme, Kit PCR - Master Mix 2X (Promega), and $0.2 \mu \mathrm{M}$ of each primer. The reaction was conducted under the following conditions: initial denaturation at $94^{\circ} \mathrm{C}$ for $5 \mathrm{~min}, 25$ cycles of denaturation at $93^{\circ} \mathrm{C}$ for $1 \mathrm{~min}$, annealing at $63^{\circ} \mathrm{C}$ for $1 \mathrm{~min}$, extension at $72{ }^{\circ} \mathrm{C}$ for $2 \mathrm{~min}$, and a final extension at $72{ }^{\circ} \mathrm{C}$ for $10 \mathrm{~min}$.

For DGGE analysis and to clone bands, we used the 341F-GC/907 pair of primers (Muyzer et al., 1993; Lane, 1991), which also served to amplify the gel band when deprived of the GC-clamp (Table 2). The PCR reaction was carried out in a final volume of $30 \mu \mathrm{L}$, which contained $3 \mu \mathrm{L}$ of template DNA, $1.25 \mu \mathrm{M}$ of $\mathrm{MgCl}_{2}, 0.25 \mu \mathrm{M}$ of dNTP, $2.5 \mathrm{U}$ of Taq DNA polymerase enzyme, Kit PCR - Master Mix 2X (Promega) and $0.2 \mu \mathrm{M}$ of each primer. The reaction was conducted under the following conditions: initial denaturation at $95^{\circ} \mathrm{C}$ for $5 \mathrm{~min}, 32$ cycles of denaturation at $95^{\circ} \mathrm{C}$ for $1 \mathrm{~min}$, annealing at $53^{\circ} \mathrm{C}$ for $1 \mathrm{~min}$, extension at $72{ }^{\circ} \mathrm{C}$ for $2 \mathrm{~min}$, and a final extension at $72{ }^{\circ} \mathrm{C}$ for $10 \mathrm{~min}$.

The amplification products were analyzed by electrophoresis by running the samples in a $1 \%$ agarose gel, which was subsequently stained with $10 \mathrm{ppm}$ of ethidium bromide, and photographed in a Kodak GL100 system. A 1-Kb DNA Ladder (Invitrogen) was used to determine the molecular weight and DNA concentration. The gels were stained with ethidium bromide solution.

\subsection{Denaturing gradient gel electrophoresis}

After confirming that the samples were amplified, $30 \mu \mathrm{L}$ of each amplified sample was loaded onto a gel, and $5 \mu \mathrm{L}$ of dye were added on top $(0.5 \%$ bromophenol blue, $40 \%$ sucrose, $0.1 \mathrm{~mol} / \mathrm{L}$ of EDTA, $5 \%$ of SDS). The final samples were next submitted to a chemical denaturing gradient electrophoresis. A 45\% - 65\% denaturing urea-formamide TAE $0.5 \mathrm{X}$ gradient $(120 \mathrm{~V}-70 \mathrm{~mA})$ was applied for $16 \mathrm{~h}$, using Bio-Rad equipment. As a marker for gels normalization, we used a mixed $16 \mathrm{~S}$ rDNA sample derived from the amplification of this gene from four microbial species (Sinorhizobium fredii, Azospirillum brasilense, Burkholderia sp., Rhizobium tropici IIA), whose bands position on the gel is well known.

The gels were next stained with ethidium bromide $(1 \mu \mathrm{g} / \mathrm{mL})$ for $30 \mathrm{~min}$, washed in distilled water for $5 \mathrm{~min}$, and observed in a transilluminator under ultraviolet light. The image of the gel was digitized and analyzed using BioNumerics software package. A similarity dendrogram between treatments was obtained, using the Jaccard similarity coefficient and the unweighted pair-group method (UPGMA).

\subsection{Multivariate analysis}

For the multivariate analysis we used the main component analysis (PCA). Using the binary matrices to make the PCA. In order to relate the structure of the bacterial community to the diets offered and organisms studied. For this, a Non-Metric Multidimensional Scaling (NMDS) analysis was performed with the presence and absence data of bands using the Jaccard index. The coordinates calculated in the ordering space by NMDS were used in the PCA. The binary matrix was exported from Bionumerics and imported into PAST V 3.2 to make the PCA (Hammer et al., 2001).

\subsection{Construction of sequencing clones library}

For cloning purposes, we used the primers 341F-GC and 907R. The bands that showed the greatest contrast in DGGE were cut and re-amplified, using primer $341 \mathrm{~F}$ without the GC clamp. Once the amplification was confirmed, the samples were purified using the OMEGA BioTek Kit, following the manufacturer's instruction.

The cloning was performed according to the pGEM-T easy vector protocol (Promega). The system relies on the insertion of the fragment to be cloned, in this case $16 \mathrm{~S}$ rDNA, into a plasmid vector. The enzyme T4 DNA ligase was used to catalyze the bond between the adhesive ends of the open plasmid (thymine) and the adenine residues at the ends of the insert generated during the amplification by the Taq polymerase. The products of the vector/insert bonds were introduced into chemically competent cells of Escherichia coli DH5 $\alpha$, and plated in LuriaBertani (LB)/ampicillin medium. Petri dishes presenting white colonies contained plasmids with cloned 16S rDNA, while those with blue colonies contained plasmids without $16 \mathrm{~S}$ rDNA. Five white colonies from each plate were inoculated into $5 \mathrm{~mL}$ of LB liquid medium, and maintained at $37^{\circ} \mathrm{C}$ for $12 \mathrm{~h}$ in a shaking incubator. DNA plasmids were next purified from these cultures, using the Plasmid OMEGA E.Z.N.A. Kit, according to the manufacturer's instructions.

\subsection{Phylogenetic analysis of the sequences}

Isolates and plasmid DNAs were sequenced by Macrogen (The Netherlands).

The sequences obtained were compared with those in the National Center for Biotechnology Information (NCBI) database, using the BLAST program (Altschul et al., 1997), with the aim of identifying the most evolutionarily similar sequences available, and building a phylogenetic tree. The sample sequences were aligned with other sequences of the same taxonomic affiliation according to their phylum or class. From this alignment, a phylogenetic tree was built, applying the Neighbor-Joining method and the Kimura 2-parameter model in the Mega 6 Program, Bootstrap Analysis, with 1000 replicates (Tamura et al., 2013).

\subsection{Access number of nucleotide sequences}

The sequences recovered from DGGE bands were deposited in GenBank, under accessions (KX665561.1, KX665562.1, KX665563.1, KX665564.1, KX665585.1, KX665567.1, KX665568.1, KX665569.1, KX665570.1, KX902233.1, KX665572.1, KX665571.1, KX665574.1, 


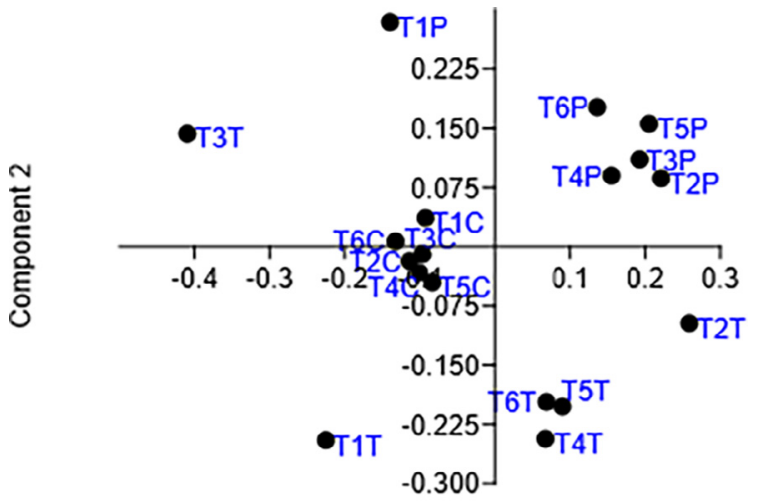

\section{Component 1}

Fig. 1. Composition of the intestinal bacterial community of invertebrates in relation to the diet offered. The main coordinate analysis was performed using "Non-Metric Multidimensional Scaling" (NMDS) with the presence and absence data of bands using the Jaccard index. Total DNA samples isolated from the intestinal tract of three species of saprophagous invertebrates, which were supplied up to six different diets. Trigoniulus corallinus: (T1T), (T2T), (T3T), (T4T), (T5T), (T6T); Cubaris murina: (T1C), (T2C), (T3C), (T4C), (T5C), (T6C); Pycnoscelus surinamensis: (T1P), (T2P), (T3P), (T4P), (T5P), (T6P).

KX665573.1, KX665576.1, KX665575.1, KX665577.1, KX665578.1, KX665579.1, KX665581.1, KY552664.1, KX665583.1 e KX665582.1).

\section{Results}

\subsection{Principal component analyzes (PCA)}

To compare the microbial communities of the three invertebrates, the $16 \mathrm{~S}$ region of rDNA was amplified using total DNA extracted from the intestine of five individuals of each species. According to the analysis of the main component the main factor that contributed to the clusters was the source of microbial DNA, ie, invertebrate species (Figs. 1 and 2). These results reveal the differences in the degrees of intimacy and complexity of microbial populations that can be found in the intestinal tract of different saprophagous individuals.

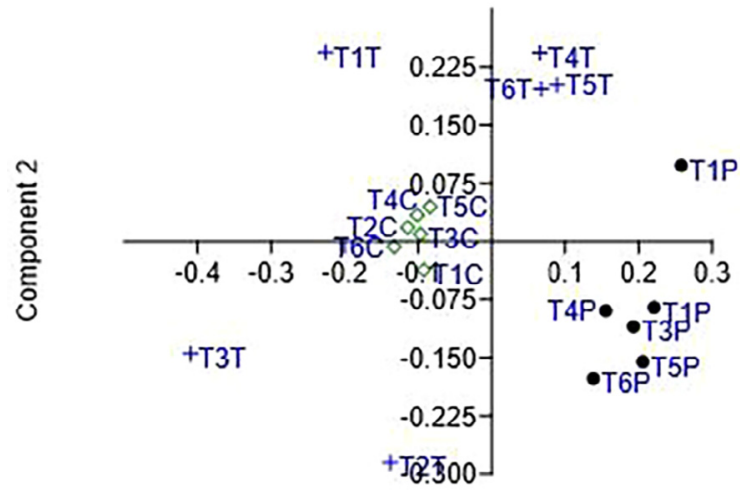

Component 1

Fig. 2. Composition of the intestinal bacterial community of invertebrates in relation to the diet offered. The main coordinate analysis was performed using "Non-Metric Multidimensional Scaling" (NMDS) with the presence and absence data of bands using the Jaccard index. Domain Actinobacteria, samples of total DNA isolated from the intestinal tract of the three species of saprophagous invertebrates, which were supplied up to six different diets. Trigoniulus corallinus: (T1T), (T2T), (Т3T), (T4T), (T5T), (T6T); Cubaris murina: (T1C), (T2C), (T3C), (T4C), (T5C), (T6C); Pycnoscelus surinamensis: (T1P), (T2P), (T3P), (T4P), (T5P), (T6P).
The clusters show low influence of the diets offered, which may (related to diet composition). The structure of the T5 and T6 treatments includes different recalcitrant materials (corn cob and coconut fiber), which in this case did not induce significant changes to the treatments. However, they include the same legume (Gliricidia), which could be responsible for the clusters.

Another interesting fact is that the three species evaluated have similar eating habits and palatability.

\subsection{Sequencing analysis of bands extracted from DGGE gels}

Of 112 bands visualized on the gel, 52 were cut. These cut bands were conditioned in TEA-BUFFER, which was used to remove the DNA from the polyacrylamide gel. This removal allowed a second PCR amplification. After PCR confirmation, we noticed that only 23 fragments were amplified. The clone sequences were compared with 16S rDNA database sequences from the NCBI, and classified by the creation of phylogenetic affiliation groups (Fig. 4). We obtained a phylogenetic tree with sequences of 447 base pairs, which allowed us phylogenetic inference. Considering the multiple alignment of all sequences and a base substitution model. However, these sequences were excellent for inferences between groups (family). For this reason, only sequences of cultivable bacteria were used to build the phylogenetic tree, as shown in (Fig. 4). The samples belong to the families Enterobacteriaceae, Brucellaceae, Rhizobiaceae, Bacillaceae, and Chitinophagaceae.

The sample sequences were aligned with other sequences of the same taxonomic affiliation, according to closest Genus, Family and Fhylum. These values, along with taxonomic units, coverage, identity, fragment size, and access number, are presented in Table 3. Some sequences were very similar, explained by the fact that samples amplified by PCR can produce more than one DGGE band, derived from multiple and heterogeneous rDNA operons.

From the sequences obtained in Hit 2 and represented by the letter (B), members of three phylogenetic lines were identified, affiliated with the domain Bacteria, which include: Proteobacteria (Gamma and Alpha), Bacteroidetes, and Firmicutes. Thus, a low phylogenetic diversity occurred. Within phylum, we identified the following nine genera: Enterobacter, Chitinophaga, Buttiauxella, Ochrobactrum, Serratia, Kaistia, Bacillus, Kluyvera, and Pantoea (Fig. 3A/C).

\section{Discussion}

\subsection{Bacterial community structure}

In this study, PCA revealed that there were no strong differences between diets, but strong differences between species (Figs. 1 and 2). One of the hypotheses is that the long incubation period (60 days) can stabilize the microbial population found in the intestinal tract of the three invertebrates studied, which causes a Stand-by. The other hypothesis may be related to the sample size. Similar data were found by Passos (2010), while analyzing the bacterial diversity of the intestinal tract of the species Trigoniulus corallinus subjected to two different diets: foliage (Mimosa caesalpiniifolia) and grass (Paspalum notatum). The incubation period considered varied between 15 and 75 days. The most interesting observation was that samples obtained after an incubation period of 75 days were grouped with the control treatment, which demonstrated the resilience of microbes found in the intestinal tract of the species $T$. corallinus. When the time of incubation was 15 days, the results obtained differed from those of the others, caused by the change and adaptation of bacteria in relation to the source of food.

A similar result was also shown by Knapp et al (2009), when analyzing bacteria from the diplopoda species Cylindroiulus fulviceps, which were incubated for 45 days in bovine manure, and with two different plant residues, Vaccinium gaultheroides and Luzula sp. The authors observed that the community of bacteria, archaea, and fungi was poorly influenced by the substrate ingested during the 45 days. 
Table 3

Classification of cloning sequences for the domain Bacteria from DGGE bands by comparative analysis between BLAST and NCBI.

\begin{tabular}{|c|c|c|c|c|c|c|c|}
\hline Bands & Hits & Closest relative & GenBank & Identity (\%) & Coverage (\%) & Fhylum & Family \\
\hline \multirow[t]{2}{*}{ 1- T1Tr (KX665561.1) } & A & Uncultured bacterium partial 16S rRNA & HE647140 & 90 & 93 & - & - \\
\hline & B & Enterobacter aerogenes BD18ACC-R05 & HF585066 & 99 & 61 & Proteobacteria (Gamma) & Enterobacteriaceae \\
\hline \multirow[t]{2}{*}{ 2- $\mathrm{T} 2 \operatorname{Tr}(\mathrm{KX665561.1)}$} & A & Uncultured bacterium partial 16S rRNA & HE647140 & 89 & 92 & - & - \\
\hline & B & Enterobacter aerogenes BD18ACC-R05 & HF585066 & 99 & 60 & Proteobacteria (Gamma) & Enterobacteriaceae \\
\hline \multirow[t]{2}{*}{ 3- $\mathrm{T} 2 \operatorname{Tr}(\mathrm{KX} 665563.1)$} & A & Uncultured bacterium partial 16S rRNA & AJ863366 & 99 & 57 & - & - \\
\hline & $\mathrm{B}$ & Chitinophaga terrae KP01 & NR_041540 & 97 & 57 & Bacteroidetes & \\
\hline \multirow[t]{2}{*}{ 4- $\mathrm{T} 3 \operatorname{Tr}(\mathrm{KX} 665564.1)$} & A & Enterobacter aerogenes A23 & KC434976 & 100 & 60 & Proteobacteria (Gamma) & Enterobacteriaceae \\
\hline & B & Enterobacter aerogenes Lb15 & KF726081 & 99 & 60 & Proteobacteria (Gamma) & Enterobacteriaceae \\
\hline \multirow[t]{2}{*}{ 5- $\mathrm{T} 3 \operatorname{Tr}(\mathrm{KX665585.1)}$} & A & Uncultured bacterium partial 16S rRNA & HE647137 & 88 & 87 & - & - \\
\hline & B & Buttiauxella brennerae LHC20 & КС951916 & 95 & 56 & Proteobacteria (Gamma) & Enterobacteriaceae \\
\hline \multirow[t]{2}{*}{ 6- T4Tr (KX665567.1) } & A & Uncultured bacterium partial 16S rRNA & HE647137 & 89 & 94 & - & - \\
\hline & B & Enterobacter aerogenes A23 & KC434976 & 99 & 61 & Proteobacteria (Gamma) & Enterobacteriaceae \\
\hline \multirow[t]{2}{*}{ 7-T4Tr (KX665568.1) } & A & Uncultured bacterium partial 16S rRNA & HE647137 & 88 & 94 & - & - \\
\hline & $\mathrm{B}$ & Enterobacter aerogenes A23 & KC434976 & 98 & 60 & Proteobacteria (Gamma) & Enterobacteriaceae \\
\hline \multirow[t]{2}{*}{ 8- $\operatorname{T5Tr}(\mathrm{KX} 665569.1)$} & A & Uncultured bacterium partial 16S rRNA & HE647145 & 93 & 87 & - & - \\
\hline & B & Ochrobactrum sp. LM19 & KF769963 & 99 & 55 & Proteobacteria (Alpha) & Brucellaceae \\
\hline \multirow[t]{2}{*}{ 9- $\mathrm{T} 5 \operatorname{Tr}(\mathrm{KX} 665570.1)$} & A & Uncultured bacterium partial 16S rRNA & HE647148 & 93 & 91 & - & - \\
\hline & B & Ochrobactrum sp. LM19 & KF769963 & 99 & 57 & Proteobacteria (Alpha) & Brucellaceae \\
\hline \multirow[t]{2}{*}{ 10- $\mathrm{T} 6 \operatorname{Tr}(\mathrm{KX} 902233.1)$} & A & Uncultured bacterium partial $16 \mathrm{~S}$ rRNA & HE647140 & 89 & 86 & - & - \\
\hline & $\mathrm{B}$ & Serratia ureilytica NiVa 51 & NR_042356 & 95 & 56 & Proteobacteria (Gamma) & Enterobacteriaceae \\
\hline \multirow[t]{2}{*}{ 11- T6Tr (KX665572.1) } & A & Uncultured bacterium partial 16S rRNA & HE647138 & 91 & 86 & - & - \\
\hline & $\mathrm{B}$ & Kaistia granuli N106 & HM244947 & 99 & 54 & Proteobacteria (Alpha) & Rhizobiaceae \\
\hline \multirow[t]{2}{*}{ 12- $\mathrm{T} 6 \operatorname{Tr}(\mathrm{KX665571.1)}$} & A & Bacillussp. Pb-WC11221 & JX913836 & 99 & 56 & Firmicutes & Bacillaceae \\
\hline & B & Bacillus flexus CSMCRI-1108 & JQ665371 & 99 & 56 & Firmicutes & Bacillaceae \\
\hline \multirow[t]{2}{*}{ 13- T2Cu (KX665574.1) } & A & Uncultured bacterium partial $16 \mathrm{~S}$ rRNA & HE647137 & 90 & 79 & - & - \\
\hline & $\mathrm{B}$ & Kluyvera cryocrescens KC46282 & KC686601 & 99 & 53 & Proteobacteria (Gamma) & Enterobacteriaceae \\
\hline \multirow[t]{2}{*}{ 14- T2Cu (KX665573.1) } & A & Uncultured bacterium partial 16S rRNA & HE647137 & 89 & 94 & - & - \\
\hline & $\mathrm{B}$ & Pantoea agglomerans 4GW7 & GU991862 & 100 & 61 & Proteobacteria (Gamma) & Enterobacteriaceae \\
\hline \multirow[t]{2}{*}{ 15- T3Cu (KX665576.1) } & A & Uncultured bacterium partial $16 \mathrm{~S}$ rRNA & HE647140 & 90 & 93 & - & - \\
\hline & B & Pantoea agglomerans 4GW7 & GU991862 & 99 & 61 & Proteobacteria (Gamma) & Enterobacteriaceae \\
\hline \multirow[t]{2}{*}{ 16- Т3Cu (KX665575.1) } & A & Uncultured bacterium partial 16S rRNA & HE647137 & 89 & 94 & - & - \\
\hline & B & Enterobacter aerogenes A23 & KC434976 & 99 & 61 & Proteobacteria (Gamma) & Enterobacteriaceae \\
\hline \multirow[t]{2}{*}{ 17- T4Cu (KX665577.1) } & A & Uncultured bacterium clone B137 & JX515438 & 99 & 93 & - & - \\
\hline & B & Kaistia granuli N106 & HM244947 & 99 & 93 & Proteobacteria (Alpha) & Rhizobiaceae \\
\hline \multirow[t]{2}{*}{ 18- T5Cu (KX665578.1) } & A & Uncultured bacterium partial 16S rRNA & HE647140 & 90 & 92 & - & - \\
\hline & B & Enterobacter aerogenes A23 & KC434976 & 99 & 60 & Proteobacteria (Gamma) & Enterobacteriaceae \\
\hline \multirow[t]{2}{*}{ 19- T6Cu (KX665579.1) } & A & Uncultured bacterium partial 16S rRNA & HE647138 & 92 & 90 & - & - \\
\hline & $\mathrm{B}$ & Kaistia granuli N106 & HM244947 & 99 & 56 & Proteobacteria (Alpha) & Rhizobiaceae \\
\hline \multirow[t]{2}{*}{ 20- T1Py (KX665581.1) } & A & Uncultured bacterium partial 16S rRNA & HE647140 & 90 & 93 & - & - \\
\hline & $\mathrm{B}$ & Enterobacter aerogenes A23 & KC434976 & 99 & 61 & Proteobacteria (Gamma) & Enterobacteriaceae \\
\hline \multirow[t]{2}{*}{ 21- Т2Ру (КY552664.1) } & A & Uncultured bacterium clone KD9-162 & AY218659 & 92 & 61 & - & - \\
\hline & $\mathrm{B}$ & Chitinophaga sp. RA12 & JN585676 & 91 & 61 & Bacteroidetes & Chitinophagaceae \\
\hline \multirow[t]{2}{*}{ 22- Т5Рy (КX665583.1) } & A & Uncultured bacterium partial 16S rRNA & AJ863366 & 99 & 60 & - & - \\
\hline & $\mathrm{B}$ & Chitinophaga terrae KP01 & NR_041540 & 97 & 60 & Bacteroidetes & Chitinophagaceae \\
\hline 23- Т5Рy (KX665582.1) & A & Uncultured bacterium partial 16S rRNA & AJ863366 & 99 & 61 & & \\
\hline & B & Chitinophaga terrae KP01 & NR_041540 & 97 & 61 & Bacteroidetes & Chitinophagaceae \\
\hline
\end{tabular}

* A $=$ Hit 1 in GenBank. $\mathrm{B}=$ Hit 1 or 2 of cultivable bacteria.

Lefebvre et al. (2009), using primers specific for the domain Actinobacteria, observed several sequences in the intestinal tract of termites of the species Nasutitermes corniger. The same authors postulated the hypothesis that the community of Actinobacteria in the intestinal tract of this termite has been entirely influenced by the microbiota present in the diet supplied.

Members of the Actinobacteria phylum, inhabiting the intestine of invertebrates, are diverse and widely distributed among different families of the order Actinomycetales. The majority of the sequences related to Actinobacteria revealed the presence of new bacterial species resulting from the intestine of the invertebrates (Lefebvre et al., 2009). Beneficial microbial associations may augment integral immune defenses and help provide protection against pathogens via microbial competition, by stimulating immune responses, or through secretion of anti-microbial compounds (Kaltenpoth and Engl, 2014). Additional investigations are required to explore changes in the community of Actinobacteria that can be found in the gut of invertebrates, with respect to food components, time of diet supply, and determination of the resulting impact on the degradation of crop residues.

According to Byzov (2006), most bacteria isolated from the diplopod gut belong to Gammaproteobacteria and Actinobacteria. Among the Proteobacteria are the facultative anaerobic bacteria of the family Enterobacteriaceae, the genera Klebsiella, Enterobacter, Plesiomonas, Salmonella, Erwinia, Escherichia, and the family of Vibrionaceae of the genus Vibrio. The second-largest group of bacteria inhabiting the diplopod gut is Actinobacteria. These include the following families: Promicromonosporaceae, Cellulomonadaceae, Streptomycetaceae, and a nocardioform actinomycetes. Among these families, Streptomycetaceae prevails.

Despite a high diversity of Actinobacteria, isolated from the different species of termites, these represent only a small fraction of those present in the intestinal tract (Demura and Fukuda, 2007). A potential role of Actinobacteria in the intestinal tract of termites is related to nutrition, aiding in the degradation of lignocellulosic compounds (Demura and Fukuda, 2007).

Another important result obtained from our work is related to the band profiles of samples from the cockroach species $P$. surinamensis, which differed in relation to the other two species.

According to the data obtained from molecular analyses of the order Spirobolida represented here by the species $T$. corallinus and the order Isopoda represented by the species $C$. murina, these orders belong to the same family, that is, they have a common ancestry (Paulus, 2000). On the other hand, the species $P$. surinamensis of the order Blattodea and 


\section{(A) Phylum}

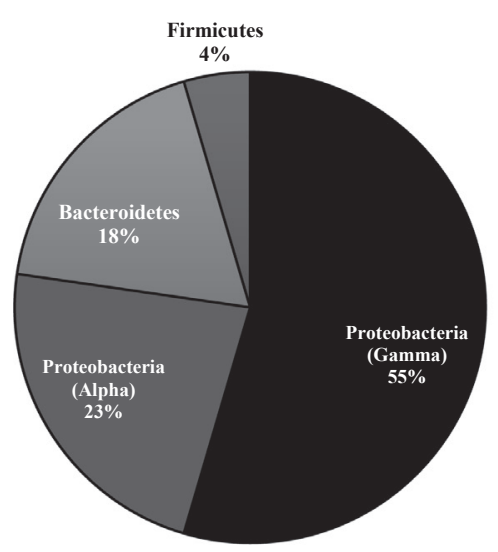

(B) Family

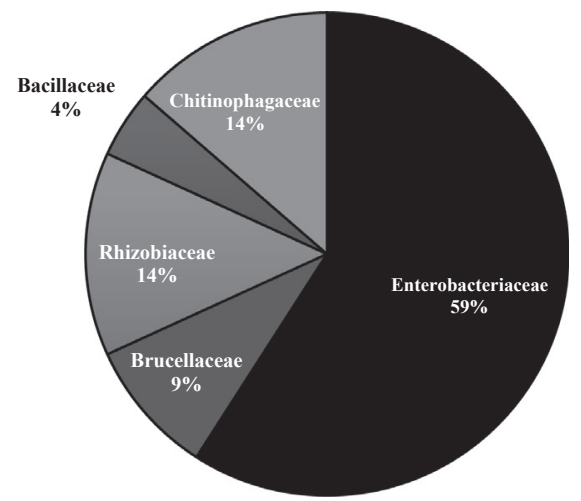

\section{(C) Genus}

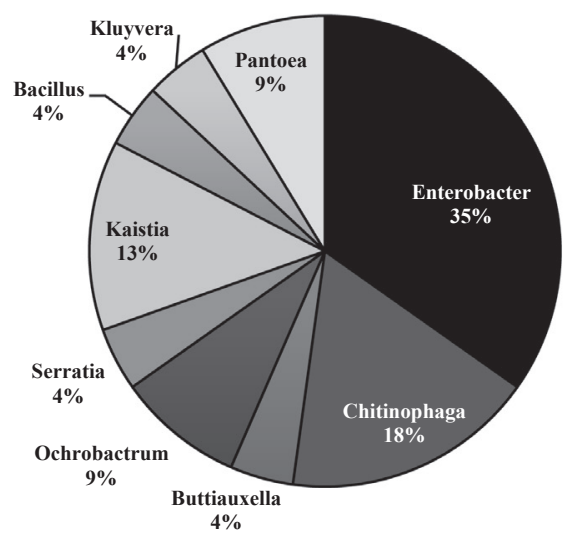

Fig. 3. Hit 2 of cloning sequences for the domain Bacteria from DGGE bands. A) Phylum, B) Family, and C) Genus.

the termites of the order Isoptera also have a common ancestor, although they are considered as belonging to different orders. Phylogenetic molecular analysis revealed that both groups belong to the same family (Inward et al., 2007; Ware et al., 2008; Djernæs et al., 2012).

Schauer et al. (2012), when studying bacteria that could be found in the intestinal tract of the cockroach Shelfordella lateralis, observed that the great differences in the structure of bacteria between cockroaches correspond to large variations of the intestinal compartment, and the concentration of hydrogen that significantly accumulates in the midgut and hindgut. The appropriateness of this information relies on the fact that the nitrogen content of plant material is attractive for invertebrates living in the soil, feeding preferentially on nitrogen-rich material.

Kunkel (1981), when studying a species of German cockroach, Blattella germanica, found that this species is highly sensitive to food deprivation and the limitation of specific nutrients, especially proteins.

\subsection{Identification of sequenced $16 S$ rDNA fragments from DGGE}

The analyses of $16 \mathrm{~S}$ rDNA clone were carried out, to be more representative from a qualitative point of view. PCR-DGGE revealed complex band profiles in different samples evaluated.

Table 3 shows the results of two Hits. The first Hit was identified with the letter (A), and is mostly formed by sequences of non-cultivable bacteria. The second Hit is identified with the letter (B), and consists of sequences of cultivable bacteria.
It is possible to observe that the sequences of cultivable bacteria in Hits 2 revealed a lower coverage but high identity, meaning that the regions of the 16S rDNA are highly conserved. In addition, this means that the organisms present in the samples from the intestinal tract of the invertebrates studied strongly relate to these sequences. However, the sequences of non-cultivable bacteria Hits 1 showed high coverage and low identities. Although the clones that were found presented a high identity with cultivable bacteria in Hit 2, most were related to noncultivable bacteria. However, in this case, the data produced by molecular analysis are relative, not allowing to establish the exact sequence identity. When the closest microbes are not described, it is difficult to deduce the possible metabolic/functional role of their phylogenetic position (Kochling, 2007).

Some samples from Hit 1 and Hit 2, showing low identity (between 88 and $97 \%$ ), possibly belong to new genera or species. However, this analysis reveals that the intestinal tract of invertebrates presents a diversity of microbial species that is still unknown. Thus, a more detailed analysis of cultivable bacteria could be carried out (involving the application of various culture media, including anaerobic media).

The class Gammaproteobacteria has been represented by the family Enterobacteriaceae, which was recognized to prevail in the intestines of several invertebrates living in the soil. Some representatives of the class Deltaproteobacteria, mainly consisting of sulfur sulfate reducing bacteria, were also affiliated to sequences from termite (Warnecke et al., 2007). Within Gammaproteobacteria, a class known by its ability to 


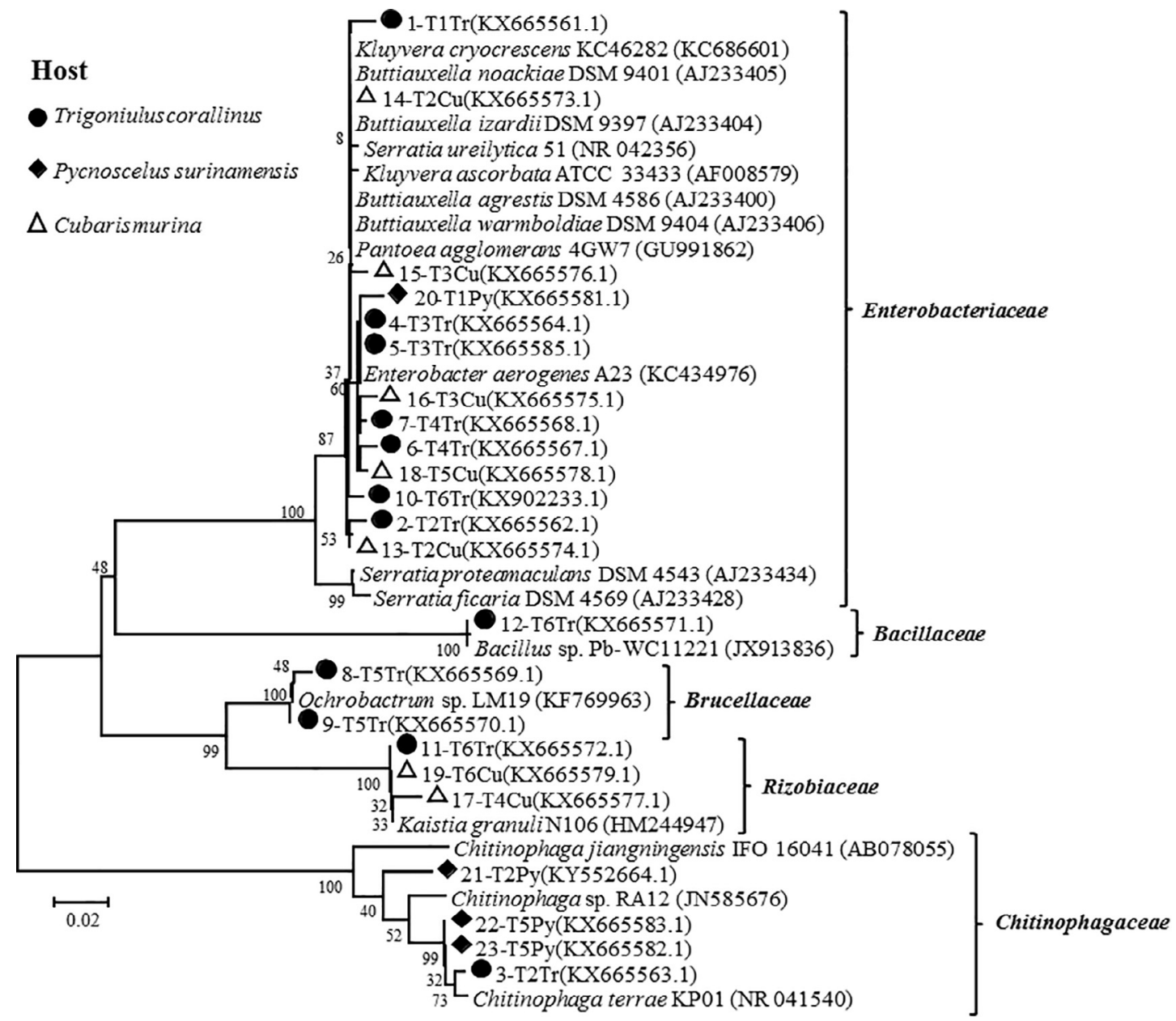

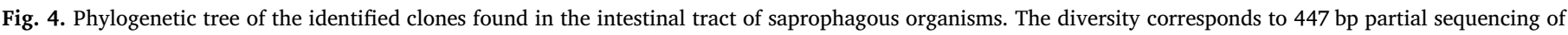

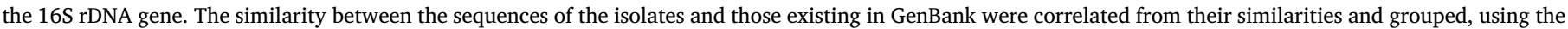
Neighbor Joining method. Bootstrap values per 1000 replicates are also reported. The program MEGA 6 was used.

metabolize several carbon compounds (Kersters et al., 2006), members of the family Enterobacteriaceae were abundantly reported in the invertebrate intestinal flora (Dillon et al., 2008; Lee et al., 2008). Theoretically, these belong to families that prevail in the intestinal tract of diplopods (Byzov et al., 1996).

The population density determined by an independent culture approach showed in this work that the genus Enterobacter was the dominant group in the intestinal tract of invertebrates, under the conditions of diets supplied (Fig. 3/C). This genus belongs to the family Enterobacteriaceae, and has already been identified as a symbiont of earthworms and termites (Koch et al., 2013).

Numerous Bacteroides phylotypes were closely related to clones resulting from the intestinal tract of termites (Su et al., 2015) and Coleoptera (Tagliavia et al., 2014). Along with members of phylum Firmicutes, this was demonstrated as prevailing in the intestine of termites and Orthoptera (Su et al., 2015; Waite et al., 2015). These include representatives with the fermentative metabolism of the phylum Bacteroidetes and Firmicutes, which assumes their contribution to decomposing vegetable residues (Hongoh et al., 2006). These intestinal microbes are described as mediators of biogeochemical cycles, such as the carbon cycle in the biomass decomposition of plant residue (Bignell et al., 1997; Fierer et al., 2009), and nitrogen fixation (Fox-Dobbs et al., 2010).

Scientific research on the composition of the bacterial community in arthropods comes to a great intensity. Yun et al. (2014) characterized insect-associated gut bacteria of 305 individuals belonging to 218 species in 21 taxonomic orders. In a review Bouchon et al. (2016) synthesized current knowledge about the terrestrial microbe of isopods and identified future directions to understand the functional role of symbiotic bacteria. Esposti and Romero (2017) showed the phylum proteobacteria, which is usually dominant in marine and terrestrial environments and covers all functions associated with microbiomes.

Our study showed that gut bacteria from several invertebrate species were dominated by phylum Proteobacteria, Bacteroidetes, and Firmicutes. Proteobacteria is the most representative phylum among all insects studied so far (Jones et al., 2013; Yun et al., 2014; Horváthová et al., 2016).

However, the abundance of Proteobacteria, Bacteroidetes, and Firmicutes among cultured bacteria, in libraries of clones, could be attributed to their preference for microaerophilic environments (very low concentrations of oxygen), which were previously detected in the diplopod gut (Byzov, 2006).

Knapp et al. (2010), while analyzing samples derived from the intestinal tract of diplopods $C$. fulviceps, under anaerobic culture conditions, isolated facultative anaerobic bacteria of phylum Firmicutes (Bacillales and Clostridiales). However, no representative of Bacteroidetes and Deltaproteobacteria has been isolated.

The phylum Actinobacteria was not identified in the clone sequences. Although these are well represented in cultures collection, they are often underrepresented in clone libraries (Hugenholtz et al., 1998). Owing to the difficulty of cell lysis and its high GC content, DNA extraction and amplification by PCR might be difficult (Mühling et al., 2008; Feinstein et al., 2009). For these reasons, the lack of Actinobacteria within clone libraries could be attributed to its methodological 
restriction (Knapp et al., 2010).

This research is the first symbiotic investigation with these three species of soil invertebrates (T. corallinus, C. murina and $P$. surinamensis), which are closely related to the decomposition of organic matter. This symbiosis between saprophagous invertebrates and microbes acts as a filter in the soil, implicating it in the regulation of nutrient and carbon cycling. Although this symbiosis is already known, the specific function of each microbial species within the host is still unknown. However, the structure and dynamics of the microbial community that could be found in the intestinal tract of the invertebrates cannot be evaluated in isolation, by a single methodology. Cross analyses of the results obtained by different methods are therefore necessary.

\section{Conclusions}

PCA analyzes revealed the existence of a correlation between the structures of isolated invertebrate bacteria of the same species, which were strongly grouped after a long incubation period. In order to obtain more significant data, the cloning analyzes of the DGGE bands were represented by sequences affixed to the phylum Proteobacteria, Firmicutes and Bacteroidetes. The genus Enterobacter was the group that prevailed in the intestinal tract of the three invertebrates. Therefore we conclude that environmental and phylogenetic criteria of the host can condition the development and diversity of microorganisms present in the intestinal tract of invertebrates. Any global assessment of microorganisms associated with the invertebrate intestine contributes significantly to the scarcity of information on these interactions. Current research for nutritional ecology has new alternatives, from genomic advances.

\section{Acknowledgements}

The authors thank CAPES and CNPq for funding, the University of Coimbra for partnership in laboratory analyzes, the Brazilian Agricultural Research Corporation - Embrapa, to provide research, space and support materials, and the Federal Rural University of Rio de Janeiro.

\section{Appendix A. Supplementary data}

Supplementary data associated with this article can be found, in the online version, at https://doi.org/10.1016/j.apsoil.2018.07.009.

\section{References}

Altschul, S.F., Madden, T.L., Schäffer, A.A., Zhang, J., Zhang, Z., Miller, W., Lipman, D.J., 1997. Gapped BLAST and PSI-BLAST: a new generation of protein database search programs. Nucleic Acids Res. 25, 3389-3402.

Bevins, C.L., Salzman, N.H., 2011. The potter's wheel: the host's role in sculpting its microbiota. Cell. Mol. Life Sci. 68, 3675-3685.

Bignell, D.E., Eggleton, P., Nunes, L., Thomas, K.L., 1997. Termites as Mediators of Carbon Fluxes in Tropical Forests: Budgets for Carbon dioxide and Methane Emissions. Eds. Chapman \& Hall, London.

Bouchon, D., Zimmer, M., Dittmer, J., 2016. The terrestrial isopod microbiome: an all-inone toolbox for animal-microbe interactions of ecological relevance. Front. Microbiol. 7, 1472.

Brucker, R.M., Bordenstein, S.R., 2011. The roles of host evolutionary relationships (Genus: Nasonia) and development in structuring microbial communities. Evolution 66, 349-362.

Byzov, B.A., 2006. Intestinal Microbiota of Millipedes. Eds. Springer, Heidelberg.

Byzov, B.A., Chernjakovskaya, T.F., Zenova, G.M., Dobrovolskaya, T.G., 1996. Bacterial communities associated with soil diplopods. Pedobiologia 40, 67-79.

Byzov, B.A., Nechitaylo, T.Y., Bumazhkin, B.K., Kurakov, A.V., Golyshin, P.N., Zvyagintsev, D.G., 2009. Culturable microorganisms from the earthworm digestive tract. Microbiology 78, 360-368.

Cazemier, A.E., Hackstein, J.H.P., Op den Camp, H.J.M., Rosenberg, J., Van der Drift, C., 1997. Bacteria in the intestinal tract of different species of arthropods. Microb. Ecol. 33, 189-197.

Cragg, S.M., Beckham, G.T., Bruce, N.C., Bugg, T.D.H., Distel, D.L., Dupree, P., Etxabe, A.G., Goodell, B.S., Jellison, J., McGeehan, J.E., McQueen-Mason, S.J., Schnorr, K.,
Walton, P.H., Watts, J.E.M., Zimmer, M., 2015. Lignocellulose degradation mechanisms across the Tree of Life. Curr. Opin. Chem. Biol. 29, 108-119.

Demura, T., Fukuda, H., 2007. Transcriptional regulation in wood formation. Trends Plant Sci. 12, 64-70.

Dillon, R.J., Dillon, V.M., 2004. The gut bacteria of insects: nonpathogenic interactions. Annu. Rev. Entomol. 49, 71-92.

Dillon, R.J., Webster, G., Weightman, A.J., Dillon, V.M., Blanford, S., Charnley, A.K., 2008. Composition of Acridid gut bacterial communities as revealed by 16S rRNA gene analysis. J. Invertebrate Pathol. 97, 265-272.

Djernæs, M., Klass, K.-D., Picker, M.D., Damgaard, J., 2012. Phylogeny of cockroaches (Insecta, Dictyoptera, Blattodea), with placement of aberrant taxa and exploration of out-group sampling. Syst. Entomol. 37, 65-83.

Douglas, A.E., 2009. The microbial dimension in insect nutritional ecology. Funct. Ecol. 23, 38-47.

Engel, P., Moran, N.A., 2013. The gut microbiota of insects- diversity in structure and function. FEMS Microb. Rev. 37, 699-735.

Esposti, M.D., Romero, E.M., 2017. The functional microbiome of arthropods. PLoS One 12 (5), 1-26.

Feinstein, L.M., Sul, W.J., Blackwood, C.B., 2009. Assessment of bias associated with incomplete extraction of microbial DNA from soil. Appl. Environ. Microbiol. 75, 5428-5433.

Fierer, N., Strickland, M.S., Liptzin, D., Bradford, M.A., Cleveland, C.C., 2009. Global patterns in belowground communities. Ecol. Lett. 12, 1238-1249.

Fox-Dobbs, K., Doak, D.F., Brody, A.K., Palmer, T.M., 2010. Termites create spatial structure and govern ecosystem function by affecting N2 fixation in an East African savanna. Ecology 91, 1296-1307.

Frese, S.A., Benson, A.K., Tannock, G.W., Loach, D.M., Kim, J., Zhang, M., Oh, P.L., Heng, C.K., Patil, P.B., Juge, N., Mackenzie, D.A., Pearson, B.M., Lapidus, A., Dalin, E., Tice, H., Goltsman, E., Land, M., Hauser, L., Ivanova, N., Kyrpides, N.C., Walter, J., 2011. The evolution of host specialization in the vertebrate gut symbiont Lactobacillus reuteri. PLoS Genet. 7, 1-16.

Hammer, O., Harper, D.A.T., Ryan, P.D., 2001. PAST: paleontological statistic software package for education and data analysis. Paleontol. Eletronica 4, 1-9.

Heuer, H., Krsek, M., Baker, P., Smalla, K., Wellington, E.M.H., 1997. Analysis of actinomycete communities by specific amplification of genes encoding 16S rRNA and gel electrophoretic separation in denaturing gradients. Appl. Environ. Microbiol. 63, 3233-3241.

Hongoh, Y., Ekponprasit, L., Inoue, T., Moriya, S., Trakulnaleamsai, S., Ohkuma, M., Noparatnaraporn, N., Kudo, T., 2006. Intracolony variation of bacterial gut microbiota among castes and ages in the fungus-growing termite Macrotermes gilvus. Mol. Ecol. 15, 505-516.

Horváthová, T., Babik, W., Bauchinger, U., 2016. Biofilm feeding: microbial colonization of food promotes the growth of a detritivorous arthropod. ZooKeys 577, 25-41.

Hugenholtz, P., Goebel, B.M., Pace, N.R., 1998. Impact of cultureindependent studies on the emerging phylogenetic view of bacterial diversity. J. Bacteriol. 180, 4765-4774.

Inward, D., Beccaloni, G., Eggleton, P., 2007. Death of an order: a comprehensive molecular phylogenetic study confirms that termites are eusocial cockroaches. Biol. Lett. 3, 331-335.

Jones, R.T., Sanchez, L.G., Fierer, N., 2013. A cross-taxon analysis of insect-associated bacterial diversity. PLoS One 8, 1-10.

Kaltenpoth, M., Engl, T., 2014. Defensive microbial symbionts in Hymenoptera. Funct. Ecol. 28, 315-327.

Kersters, K., De Vos, P., Gillis, M., Swings, J., Vandamme, P., Stackebrandt, E., 2006. Introduction to the Proteobacteria, 3rd ed. Springer, New York.

Knapp, B.A., Seeber, J., Podmirseg, S.M., Rief, A., Meyer, E., Insam, H., 2009. Molecular fingerprinting analysis of the gut microflora of Cylindroiulus fulviceps (Diplopoda). Pedobiologia 52, 325-336.

Knapp, B.A., Seeber, J., Rief, A., Meyer, E., Insam, H., 2010. Bacterial community composition of the gut microbiota of Cylindroiulus fulviceps (Diplopoda) as revealed by molecular fingerprinting and cloning. Folia Microbiol. 55, 489-496.

Koch, H., Abrol, D.P., Li, J., Shimid-Hempel, P., 2013. Diversity and evolutionary patterns of bacterial gut associates of corbiculate bees. Mol. Ecol. 22, 2028-2044.

Kochling, T., 2007. Biodiversidad microbiana de sedimentos marinos y su papel em ladegradacion anaerobia de los sulfonatos de alquilbenceno leneales. [tese]. Universidad Autónoma de Madrid, Madrid.

König, H., Varma, Ajit, 2006. Intestinal Microorganisms of Termites and Other Invertebrates. Eds. Springer, Heidelberg.

Kunkel, J.G., 1981. A minimal model of metamorphosis: fat body competence to respond to juvenile hormone. Eds. Plenum, New York.

Lane, D.J., 1991. 16S/23S rRNA Sequencing. Eds. John Wiley and Sons, New York.

Lee, A.H., Husseneder, C., Hooper-Bui, L., 2008. Culture-independent identification of gut bacteria in fourth-instar red imported fire ant, Solenopsis invicta BUREN, larvae. J. Invertebrate Pathol. 98, 20-33.

Lefebvre, T., Miambi, E., Pando, A., Diouf, M., Rouland-Lefèvre, C., 2009. Gut -specific actinobacterial community structure and diversity associated with the wood-feeding termite species, Nasutitermes corniger (Motschulsky) described by nested PCR-DGGE analysis. Insect Soc. 56, 269-276.

Ley, R.E., Hamady, M., Lozupone, C., Turnbaugh, P.J., Ramey, R.R., Bircher, J.S., Schlegel, M.L., Tucker, T.A., Schrenzel, M.D., Knight, R., Gordon, J.I., 2008. Evolution of mammals and their gut microbes. Science 320, 1647-1651.

Li, L., Fröhlich, J., König, H., 2006. Cellulose Digestion in the Termite Gut. Eds. Springer, Heidelberg.

Mühling, M., Woolven-Allen, J., Murrell, J.C., Joint, I., 2008. Improved group-specific PCR primers for denaturing gradient gel electrophoresis analysis of the genetic diversity of complex microbial communities. ISME J. 2, 379-392.

Muyzer, G., de Waal, E.C., Uitterlinden, A.G., 1993. Profiling of complex microbial 
populations by denaturing gradient gel electrophoresis analysis of polymerase chain reaction- amplified gene coding for 16S rRNA. Appl. Environ. Microbiol. 59, 695-700.

Ochman, H., Worobey, M., Kuo, C.H., Ndjango, J.B.N., Peeters, M., Hahn, B.H., Hugenholtz, P., 2010. Evolutionary relationships of wild hominids recapitulated by gut microbial communities. PLoS Biol. 8, 1-8.

Passos, S.R., 2010. Diversidade de microrganismos no trato intestinal e resíduos digestivo de Trigoniulus corallinus (Gervais) (Diplopoda, Spirobolia, Pachybolidae) [dissertação]. Seropédica: Universidade Federal Rural do Rio de Janeiro.

Paulus, H.F., 2000. Phylogeny of the Myriapoda - Crustacea- Insecta: a new attempt using photoreceptor structure. J. Zool. Syst. Res. 38, 189-208.

Robe, P., Nalin, R., Capellano, C., Vogel, T.M., Simonet, P., 2003. Extractio of DNA from soil. Eur. J. Soil Biol. 39, 183-190.

Roesch, L.F., Fulthorpe, R.R., Riva, A., Casella, G., Hadwin, A.K., Kent, A.D., Daroub, S.H., Camargo, F.A., Farmerie, W.G., Triplett, E.W., 2007. Pyrosequencing enumerates and contrasts soil microbial diversity. ISME J. 1, 283-290.

Schauer, C., Thompson, C.L., Brune, A., 2012. The bacterial community in the gut of the cockroach Shelfordella lateralis reflects the close evolutionary relatedness of cockroaches and termites. Appl. Environ. Microbiol. 78, 2758-2767.

Staubach, F., Baines, J.F., Künzel, S., Bik, E.M., Petrov, D.A., 2013. Host species and environmental effects on bacterial communities associated with Drosophila in the laboratory and in the natural environment. PLoS One 8, 1-12.

Su, L.J., Liu, Y.Q, Liu, H., Wang, Y., Li, Y., Lin, H.M., Wang, F. Q., Song, A.D., 2015. Linking lignocellulosic dietary patterns with gut microbial Enterotypes of Tsaitermes ampliceps and comparison with Mironasutitermes shangchengensis. Genet. Mol. Res. 14, 13954-13967.

Tagliavia, M., Messina, E., Manachini, B., Cappello, S., Quatrini, P., 2014. The gut microbiota of larvae of Rhynchophorus ferrugineus Oliver (Coleoptera: Curculionidae). BMC Microbiol. 30 (14), 136.

Tamura, G., Stecher, G., Peterson, D., Filipski, A., Kumar, S., 2013. Mega 6: molecular evolutionary genetics analysis version 6.0. Mol. Biol. Evol. 30, 2725-2729.

Tokuda, G., Watanabe, H., 2007. Hidden cellulases in termites: revision of an old hypothesis. Biol. Lett. 3, 336-339.

Waite, D.W., Dsouza, M., Biswas, K., Ward, D.F., Deines, P., Taylor, M.W., 2015. Microbial community structure in the gut of the New Zealand insect Auckland tree weta (Hemideina thoracica). Arch. Microbiol. 197, 603-612.

Ware, J.L., Litman, J., Klass, K.D., Spearman, L.A., 2008. Relationships among the major lineages of Dictyoptera: the effect of outgroup selection on dictyopteran tree topology. Syst. Entom. 33, 429-450.

Warnecke, F., Luginbühl, P., Ivanova, N., Ghassemian, M., Richardson, T.H., Stege, J.T., Cayouette, M., Mchardy, A.C., Djordjevic, G., Aboushadi, N., Sorek, R., Tringe, S.G., Podar, M., Martin, H.G., Kunin, V., Dalevi, D., Madejska, J., Kirton, E., Platt, D., Szeto, E., Salamov, A., Barry, K., Mikhailova, N., Kyrpides, N.C., Matson, E.G., Ottesen, E.A., Zhang, X., Hernandez, M., Murillo, C., Acosta, L.G., Rigoutsos, I., Tamayo, G., Grenn, B.D., Chang, C., Rubin, E.M., Mathur, E.J., Robertson, D.E., Hugenholtz, P., Leadbetter, J.R., 2007. Metagenomic and functional analysis of hindgut microbiota of a wood-feeding higher termite. Nature 450, 560-565.

Yun, J.H., Roh, S.W., Whon, T.W., Jung, M.J., Kim, M.S., Park, D.S., Yoon, C., Nam, Y.D., Kim, Y.J., Choi, J.H., Kim, J.Y., Shin, N.R., Kim, S.H., Lee, W.J., Bae, J.W., 2014. Insect gut bacterial diversity determined by environmental habitat, diet, developmental stage, and phylogeny of host. Appl. Environ. Microb. 80, 5254-5264.

Zimmer, M., Kautz, G., Topp, W., 2003. Leaf litter-colonizing microbiota: supplementary food source or indicator of food quality for Porcellio scaber (Isopoda: Oniscidea)? Eur. J. Soil Biol. 39, 209-216. 